\title{
GENEALOGIA DA INTERSUBJETIVIDADE E FIGURABILIDADE DO AFETO: WINNICOTT E MERLEAU-PONTY
}

\author{
Thamy Ayouch
}

Resumo: Aborda a questão filosófica da intersubjetividade, além da questão tradicional da alteridade. A primazia desta questão não concerne somente à filosofia, mas aparece central nas perspectivas da psicanálise e da psicopatologia, pois trata-se aqui da constituição do relacionamento com o outro, uma experiência fundada na memória do infantil, e jamais adquirida de forma definitiva. A fenomenologia merleau-pontyana explicita essa experiência cotidiana do outro. A psicanálise winnicottiana permite reconstituir uma genealogia da intersubjetividade, uma descrição de vivências arcaicas atestáveis graças à transferência, conduzindo a consequências éticas, tanto na teorização, como na clínica, e no atendimento de formas contemporâneas da psicopatologia. Ressalta como a centralidade do corpo e do outro na fenomenologia de Merleau-Ponty tem ecos na psicanálise winnicottiana e como ambas revelam um ato psíquico específico, próprio à intersubjetividade e à figuração do afeto, entre percepção e alucinação, interior e exterior, sujeito e outro.

Palavras-chave: Intersubjetividade. Afeto. Psicanálise. Fenomenologia. Merleau-Ponty (Maurice). Winnicott (Donald Woods). 


\section{A questão da intersubjetividade: além da alteridade. Problematizações}

\section{O outro e a alteridade}

Não se compreende a problemática da intersubjetividade e a operatividade desta noção se não se aborda primeiro a reflexão sobre o relacionamento do sujeito com a alteridade, seja como evidência da práxis ou como construção teórica e dificuldade da reflexão.

"Outro" em português, tanto como" otro" (espanhol)," altre" (catalão), altro (italiano), "autre, autrul" (francês), "ander" (alemão), "other" (inglês), procedem do latim "alter," pronome que designa o segundo elemento de um conjunto de dois ("unus alterque") e que significa etimologicamente a transformação do mesmo (alter < alterare: mudar). Alter tem o mesmo radical que o sânscrito "anyas", de onde provem também o grego $\alpha \dot{\alpha} \lambda \lambda \circ$ (estrangeiro, contrário do $\alpha v \tau o s:$ mesmo) e o latim alius (outro). $O$ outro é, portanto, sempre definido em função de um primeiro, concebido como variação do mesmo, cuja irredutível posição e centralidade sempre define a abordagem que se dá ao outro.

Essas considerações se acham também nas línguas semíticas: em árabe, nas duas palavras [ahar], cuja raiz triliteral significa atrasar, chegar em segundo, e غبر [rair], cujo radical quer dizer modificar. De modo igual, em hebraico, דח [aher] tem a mesma raiz que no árabe [ahar], e a outra palavra para designar o outro é ינש [chani], segundo. A primazia é a do mesmo. Nessas perspectivas, o sujeito é colocado em primeiro, e logo aparece o outro, sempre definido em função da perspectiva do sujeito. Essa centralidade do mesmo e a sua anteposição é que determinam a aparição da questão filosófica da alteridade.

Para diferenciar as questões da alteridade e da intersubjetividade, poderia se afirmar que as filosofias do cogito de Descartes, da mônada de Leibniz ou do idealismo de Berkeley abordam a questão da alteridade, ainda que limitadamente. Entretanto, elas nunca tratam da questão da intersubjetividade. $O$ problema da alteridade surge com a aparição da figura do sujeito na filosofia moderna, a partir do século XVII. No entanto, a questão não é considerada um problema para as filosofias empiristas ou puramente reflexivas, para as quais o sujeito seria só uma série de experiências psicológicas ou uma substância eterna e única. Nessas condições, o outro é somente um outro ego percebido do exterior, sem que esse modo de ser fique problemático teoricamente. $O$ problema da alteridade surge quando o ego não se reduz ao mero contato consigo mesmo, quando aparece uma parte dele que não é redutível à mera transparência a si mesmo, uma opacidade constituidora do sujeito, além da consciência, ou seja, quando são levados em conta o corpo e o incons- 
ciente. Por conseguinte, a minha encarnação e o meu ser dividido e ausente a mim mesmo são o que determinam a questão da alteridade. É porque não sou consciência pura, autoconhecida, que surge a problematicidade da questão da alteridade.

Essa questão aponta a contradição entre a evidência prática, vivida, da experiência do outro, e a dificuldade de formalizá-la teoricamente.Trata-se da problemática constituição do outro para o sujeito, que pode ser colocada de vários modos:

- em termos de filosofia da consciência, é o problema da consciência alheia: como a partir da minha consciência (que constitui o mundo e os outros), posso admitir a existência de uma consciência paradoxalmente constituída (pela minha)? Como o mundo colocado por minha consciência pode ser comum a outras consciências?

- em termos de percepção, a questão da alteridade poderia ser formulada assim: como pode haver outro sujeito da percepção, e como a minha percepção, fluxo individual, pode me unir aos outros? A afirmação de que o que um indivíduo percebe é igualmente percebido por outro, ou que percebemos um mundo comum, não pode ser da ordem da certeza, pois a percepção do outro fica inacessível diretamente para mim tanto quanto a minha é para ele/ela. Como posso apreender o outro não somente como objeto percebido, mas como polo de percepção, dispondo, como eu, de um mundo próprio, do qual participo como percebido?

- em termos de corporeidade, trata-se de saber como podem coexistir e serem compatíveis pelo menos duas abordagens do meu corpo (para mim, para o outro). Como o meu corpo abrange uma perspectiva diferente da qual eu tenho?

A fenomenologia de Maurice Merleau-Ponty permite, a meu ver, percorrer o caminho da evidência da experiência cotidiana do outro para o nível de reflexão sobre ela, passando assim da posição de uma tese natural - a existência do outro, num mundo compartilhado - para a explicitação das condições da sua afirmação. Se Merleau-Ponty retoma e amplia algumas análises dessa questão por Husserl ${ }^{1}$, a especificidade da sua postura consiste em abordar esse problema da alteridade sob uma perspectiva da intersubjetividade.

\section{Intersubjetividade e clínica contemporânea}

Cabe, então, perguntar o que é a "questão da intersubjetividade". Conforme o termo indica, não se procede a partir de uma subjetividade,

1 Edmund Husserl evoca essa questão em várias obras: na quinta das Meditações Cartesianas, no segundo volume de Idées e nos escritos Autour des Méditations cartésiennes Sur l'intersubjectivité. 
mas de uma relação. É uma abordagem totalmente diferente, na qual os termos de sujeito, consciência, ou indivíduo não são primeiros, mas resultam de uma relação precedendo e determinando a subjetividade - sem que ela se reduza, todavia, à intersubjetividade. A mudança da perspectiva, numa verdadeira "revolução copérnica"2, consiste em acordar a primazia a essa evidência prática da relação imediata com o outro. Uma filosofia da intersubjetividade não trata da questão da alteridade, não tenta saber como a minha perspectiva de sujeito é compatível com a de outros sujeitos, mas começa colocando um mundo intersubjetivo primeiro, a partir do qual resultam a minha subjetividade e a dos outros.

A primazia desta questão não concerne somente à fenomenologia e à filosofia. Ela é central nas perspectivas da psicanálise e da psicopatologia, já que se trata da constituição da intersubjetividade, uma experiência fundada na memória do infantil e que jamais é adquirida de forma definitiva. $O$ autismo, o delírio psicótico e algumas formas do que Freud chamava de "inquietante" (unheimlich) apontam precisamente uma falta de constituição da intersubjetividade.

É importante destacar que, segundo Pierre Fédida, o autismo constitui verdadeiro paradigma teórico-clínico na clínica contemporânea. A anorexia, por exemplo, ou qualquer outra forma de psicopatologia considerada contemporânea, incluindo organizações aditivas, estados-limites e psicossomatoses, podem ser pensados clinicamente pelo modelo do autismo, nas retrações do mundo, isolamentos dos outros e autossensualidades aqui vivenciadas. Como escreve Fédida (1992), "o autismo adquiriu tal nível de pertinência semioclínica que sua descrição fenomenologicamente apurada transforma-o numa verdadeira fonte de modelização". A nossa hipótese teórica e clínica é que as formas da psicopatologia contemporânea que chamamos de "loucuras contemporâneas" (Beaune \& Ayouch, 2009) - estados-limites, organizações aditivas, pseudoneuroses, depressões - estão intimamente ligadas às questões da alteridade e da intersubjetividade. Além disso, só se pode pensar numa abordagem clínica e teórica dessas formas a partir da perspectiva da intersubjetividade.

Porém não se trata aqui da psicanálise intersubjetivista. O intersubjetivismo é um movimento psicanalítico norte-americano desenvolvido a partir dos anos 1980 por Schafer, Thomas Ogden e Owen Renik, em reação à Ego-Psychology e inspirando-se na psicanálise anglo-saxônica de relação de objeto. Esse movimento apresenta a particularidade de reduzir toda a subjetividade a uma postura meramente relacional, negando a existência do pulsional. Não se objetiva aqui discutir a pertinência dessas 
teses particulares - cujo fundamento filosófico pode parecer problemático -, mas tentar ver a operatividade da intersubjetividade na teoria e na clínica analíticas.

Se a intersubjetividade designa uma anulação da tradição filosófica do solipsismo e refunda a subjetividade numa relação originária com o outro, uma série de aspectos aparecem em psicanálise:

- questiona-se o hiper-solipsismo da hipótese freudiana do narcisismo primário e as suas contradições;

- interroga-se o vínculo entre pulsão e relação de objeto;

- permite-se inscrever a psicanálise fora do biologismo e da naturalização;

- desenvolve-se uma concepção particular do afeto, e da figurabilidade dos afetos dentro desse enquadre da intersubjetividade;

- facilita-se uma abordagem clínica da psicose e de psicopatologias contemporâneas (apresentando rastros do que Freud nomeou "narcisismo secundário" e que considerou fora do alcance da psicanálise).

Se a explicitação dessa experiência cotidiana do outro é efetuada pela fenomenologia merleau-pontyana, é essencialmente a psicanálise winnicottiana que permite reconstituir uma genealogia da intersubjetividade, numa descrição de vivências arcaicas atestáveis só graças à transferência, conduzindo a consequências éticas tanto na clínica como na teorização da alteridade.

Após ter apresentado a inclusão, por Merleau-Ponty, do problema da alteridade na questão da intersubjetividade, revelando uma textura intersubjetiva do mundo e do sujeito, abordarei rapidamente a forma com que Winnicott aponta uma genealogia dessa intersubjetividade. Ressaltarei, então, como a centralidade do corpo e do outro na fenomenologia de Merleau-Ponty tem ecos na psicanálise winnicottiana e como ambas revelam um ato psíquico específico, próprio à intersubjetividade e à figuração do afeto.

A estrutura e a gênese perceptiva da intersubjetividade em Merleau-Ponty

De 1933 a 1961, a obra de Maurice Merleau-Ponty não para de colocar e redefinir a questão do relacionamento com o outro, até fazer dessa questão, numa generalização do modelo intersubjetivo, o fundamento da relação perceptiva com o mundo.

Para Merleau-Ponty, o problema da alteridade se coloca, desde o começo, fora da esfera transcendental, e é ligado à questão da percepção ou, em outros termos, a uma esfera primordial, precedendo qualquer re- 
flexão. Cabe ressaltar que a perspectiva de Merleau-Ponty é de voltar ao mundo vivido, percebido, antecessor de qualquer mundo reflexivo ou objetivado pela abordagem da ciência, e descrever a relação preobjetiva, preconsciente e dialética que o corpo estabelece com o mundo e com o outro.

Sendo assim, numa das primeiras obras, $A$ Estrutura do Comportamento, Merleau-Ponty (1942) tenta descrever o comportamento do outro enquanto aparece para a consciência perceptiva, visando uma estrutura a priorianterior à reflexão. Essa estrutura é vinculada pelo filósofo à experiência de constituição da consciência infantil, imediatamente aberta para o comportamento do outro.

É dentro dessa estrutura intersubjetiva que o sorriso do outro, por exemplo, é imediatamente compreendido pela criança, não por ser analisado e descomposto reflexivamente em elementos fisiológicos, mas por ser apreendido dentro de uma relação com o outro que precede a relação com o corpo próprio ${ }^{3}$. A percepção primitiva da criança visa mais a intenções humanas que a objetos ou qualidades puras deles: atinge primeiro rostos e gestos abordados diretamente na sua intencionalidade, $\mathrm{e}$ inscritos numa significação humana antes de serem decompostos em sensações (Merleau-Ponty, 1942, p. 181).

Essa "percepção primitiva" é infiltrada pela presença do outro, enquanto "presença humana e lacunar", dada "à criança como polo dos seus desejos e medos bem antes de um longo trabalho de interpretação que concluiria o outro de um universo de representações" (Merleau-Ponty, 1942, p. 187).

Conforme indica Bonan (2001), a integralidade da Fenomenologia da Percepção "é a minuciosa exploração desse nível transcendental intersubjetivo antepredicativo" (p. 107) nos três níveis da intercorporeidade, da intersensorialidade e do mundo da cultura. Nesse livro, a questão da intersubjetividade é relacionada com a ambiguidade que caracteriza a consciência, definida como falta de coincidência consigo mesma. Essa ambiguidade deve-se ao vínculo irredutível da consciência com o corpo,"aquele fundo afetivo que joga originariamente a consciência fora de si mesma" (Merleau-Ponty, 1945, p. 110). Em toda a sua obra, MerleauPonty teoriza uma dimensão de impessoalização do corpo, que institui uma leitura do corpo escapando ao mesmo tempo à perspectiva objetivadora da ciência reducionista e à perspectiva reflexiva de uma filosofia da consciência.

“Ce n'est pas la ressemblance de nos propres gestes et des gestes d'autrui qui peut donner à ceux-ci leur valeur expressive: l'enfant comprend le sens joyeux du sourire longtemps avant d'avoir vu son propre sourire.... Le vivant est connu longtemps avant l'inorganique" (Merleau-Ponty, 1942, p. 169). 
À medida que o sujeito se engaja em posições afetivas e práticas, o corpo desliza numa impessoalização - o sonho sendo uma forma maior dessa impessoalidade. Essa presença no mundo inter-humano não segue a intencionalidade de ato husserliana, mas uma intencionalidade operante (fungierende intentionalität). Antes de constituir o objeto (vivido, da ciência ou transcendental), essa intencionalidade unifica o mundo e a vida do sujeito e parece "nos nossos desejos, nas nossas avaliações e na nossa paisagem mais claramente do que no conhecimento objetivo" (Merleau-Ponty, 1945, p. xiii). Nessa intencionalidade, o corpo vivido é maiormente habitado sem que a sua percepção, os seus movimentos ou a sua emoção sejam retomados pela reflexão, numa relação com o mundo que, antes de ser predicativa, é carnal e corporal. Ela consiste numa ligadura inabalável entre a percepção exterior e uma realidade psíquica afetiva.

Portanto, devido à impessoalização do corpo e à depersonalização da consciência que resultam dessa intencionalidade afetiva,"o outro não é mais impenetrável para mim do que eu mesmo" (Merleau-Ponty, 1945, p. 389). Por conseguinte, o outro e eu surgimos juntos, do mesmo modo que são vinculados a consciência "saudável" e a alucinada, o passado e o presente ${ }^{4}$. Em outros termos, Merleau-Ponty está aqui comparando o modo de fenomenalização do outro com uma percepção mista (imaginação e percepção, presente e passado).

A evidência do outro é possível, além de qualquer problema teórico de anteposição do ego transcendental ou de consciência constituinte, porque não sou transparente a mim mesmo, e a minha subjetividade arrasta a impessoalidade do corpo (Merleau-Ponty, 1945, p. 405). A última frase da Fenomenologia da Percepção, de Antoine de Saint-Exupéry, ressalta esta impessoalidade interpessoal do corpo: "O homem é somente um nodo de relações, só as relações contam para o homem" (Saint-Exupéry, 1942, citado por Merleau-Ponty, 1945, p. 520).

É uma verdadeira genealogia da intersubjetividade que MerleauPonty procura, ao abordar as teorias da psicanálise e da psicologia nos seus ensinos na Sorbonne. Já no fim do segundo mês de vida, a criança sorri e ri, respondendo aos sorrisos do ambiente, o que "supõe uma relação com o outro precedendo a linguagem que aparece nesse contexto" (Merleau-Ponty, 1988, p. 16). O movimento da criança em direção à palavra é, conclui Merleau-Ponty, uma chamada constante do outro. A imita- 
ção efetuada pela criança mostra que ela percebe a intenção do gesto, mais do que o decompõe, e reconhece o outro em si mesma.

Na sua apresentação da psicanálise freudiana, o filósofo dá relevo à presença estrutural da alteridade no sujeito (através dos mecanismos de projeção e introjeção, de identificação e a triplicidade das instâncias psíquicas). A psicanálise ressaltaria o fato de que a percepção do outro precede a do corpo próprio5. Merleau-Ponty (1988) faz questão de completar o estádio do espelho descrito por Wallon pela leitura lacaniana que acentua a dimensão mais afetiva do que cognitiva dessa experiência. ${ }^{6}$

$\mathrm{O}$ modelo da intercorporeidade e intersensorialidade à base da intersubjetividade é radicalizado nos últimos textos de Merleau-Ponty, mais precisamente em "O Filósofo e a sua Sombra" e O Visível e o Invisível. A intersensorialidade das mãos (exemplo husserliano do parágrafo 37 das Idées II) é estendida a uma intercorporalidade. Do mesmo modo que a minha mão direita toca a esquerda, ela pode perceber a mão do outro; pois ambos somos copercebedores, e "o meu corpo anexa o corpo do outro neste tipo de reflexão da qual ele é paradoxalmente a sede" (Merleau-Ponty, $1953 / 1989$, p. 214). Mais radicalmente, o meu corpo próprio é concebido como uma "premonição do outro"; a minha corporeidade e a do outro são abordagens possivelmente intercambiáveis do mundo.

Essa análise é reiterada em $O$ Visível e o Invisível, através de uma filosofia da carne (philosophie de la chair). Do mesmo modo que cada experiência perceptiva é vinculada a todas as outras na unidade do meu corpo, a minha experiência e a do outro podem ser reunidas num mesmo sensível. Vidente e visível, tocante e tangível, o meu corpo é um "ser de duas camadas", referência de um visível a todos os visíveis, de um tangível a todos os tangíveis, e do mesmo modo, o corpo do outro aparece como um outro ponto de referência de um sensível a todos os sensíveis.

A reversão da carne teorizada por Merleau-Ponty - de tocado em tocante, de visível em vidente, de percebido em percebente, é o que me vincula, como sensível, a todo o sensível, e me separa dele como sentente, possibilitando que outros sententes sejam como eu, vinculados ao sensível. Com o outro, o vidente que sou se torna visível pela primeira vez, o meu corpo não se aboca somente ao mundo, mas se entrelaça com outro corpo, que é, como eu, um outro ponto de reversão da carne.

“Não há problema do alter ego", escreve Merleau-Ponty (1960b),

5 "La psychanalyse a le mérite d'avoir décrit pour la première fois les relations de l'enfant avec autrui (identifications, projections, etc.)" (Merleau-Ponty, 1988, p. 174).

6 Esta analise é reiterada no curso "Méthode en psychologie de l'enfant" (Merleau-Ponty, 1988, pp. 526527). 
porque não sou eu quem vê, nem ele quem vê, mas somos ambos habitados por uma visibilidade anônima, uma visão em geral, em virtude daquela propriedade primordial da carne de estar aqui e agora e irradiar em toda parte e para sempre, de ser individuo, mas também dimensão e universal. (p. 188)

O ser-si e ou ser-outro são meros "fragmentos de um único ser" (Merleau-Ponty, 1960b, p. 92). Assim, a carne dá conta de uma dimensão que precede a dualidade ontológica sujeito/objeto e, portanto, ultrapassa a questão da alteridade e a institui.

Esse modelo da carne permite conceber um sentente ainda não constituído como unidade, ou seja, em termos analíticos, como Ego organizado, e remete assim a momentos arcaicos da instituição da intersubjetividade. "O mundo é presente à minha carne através da sua carne", "eu formo parte dele mas não sou ele" (Merleau-Ponty, 1960b, p. 169): eis aqui fórmulas merleau-pontyanas que permitem dar conta da genealogia fantasmático-perceptiva do mundo para o recém-nascido e da continuidade-descontinuidade entre eles.

Colocarei em perspectiva essa teorização merleau-pontyana da intersubjetividade com a hipótese de Green (1999) sobre o processo afetivo como antecipação do encontro do sujeito com um outro corpo, imaginário ou presente, abrindo a possibilidade de uma interpenetração sexual e amorosa ou de uma agressão mutiladora, ambas ameaçadoras para o sujeito. $O$ afeto é, portanto, concebido ao mesmo tempo como a preparação para tal encontro e a sua previsão acelerada.

Tanto André Green como Merleau-Ponty designam a intersubjetividade na base do afeto, e do que chamo de figurabilidade do afeto: o afeto aparece como a apresentação alucinatória de uma promessa e ameaça de encontro com o outro, onde se repete a primeira intersubjetividade fundadora da psique do infante.

\section{Genealogia da intersubjetividade e afeto em Winnicott}

Apesar de Freud ter teorizado um pulsional primordial cortado do mundo e um modelo de narcisismo primário, a relação originária com o outro é, porém, para ele, fundamental na constituição da psique. Já desde o Projeto de uma psicologia científica, o vínculo com o outro é considerado necessário para o infante organizar a percepção e distanciar a excitação: só a intervenção de um primeiro outro, efetuando uma "ação específica" permite ao infante conseguir uma satisfação inatingível pelos seus próprios meios. O primeiro outro está ligado à experiência afetal de satisfação e àquela de sofrimento.

Essa primazia da relação com o outro é particularmente ressaltada por Donald Woods Winnicott. Como salienta Green (1973, p. 109), nenhum autor, na clínica e na teoria psicanalítica moderna, deu tanto relevo ao rol 
do afeto. Afirmaríamos, portanto, que essa modalização do afeto tem a ver com uma teorização da intersubjetividade. A figurabilidade do afeto depende do entrelaçamento dos afetos da criança e do entorno, num modo muito parecido à dialética da intersubjetividade teorizada por Maurice Merleau-Ponty.

J.-B. Pontalis é um dos raros autores citando uma possibilidade de comparação entre Merleau-Ponty e Winnicott. Contrariamente a Melanie Klein, que separa o interior do exterior, com o conceito de espaço transicional, Winnicott embaralha as fronteiras entre passado e presente, interior e exterior, corpo e discurso, mas sobretudo, self e outro (Pontalis, 1988). A teoria winnicottiana do entorno providencia uma verdadeira genealogia da intersubjetividade apontada por Merleau-Ponty.

\section{A intersubjetividade mãe-infante: o real e o imaginário}

O papel da "mãe suficientemente boa" é fundamental para a hominização do infante. Como indica Winnicott (1991a, pp. 19-24) em "Getting to Know your Baby", se a relação íntima com a mãe (ou pessoa em tal posição) estabelece as bases da pessoalidade da criança, do seu desenvolvimento emocional e da sua capacidade a reagir aos choques e frustrações, esse relacionamento é recíproco: a mãe precisa conhecer a criança para conjurar a sua fantasia de ter dado luz a "alguma coisa horrorosa".

O fato de que um bebê não pode existir só, e deve necessariamente fazer parte de uma relação (Winnicott, 2001, p. 115), convoca um relacionamento originário, uma intersubjetividade fundamental, a partir da qual surgem, contemporaneamente, o sujeito e o outro. A maternidade (mothering) e a criança são, por conseguinte, indissociáveis, numa total adaptação inicial da mãe que se desfaz à medida que a criança descobre a realidade.

Essa intersubjetividade originária fundamenta-se sobre a presença encarnada da mãe e o corpo é central:"O bebê deve poder sentir o calor da sua pele e a sua respiração, deve poder provar e ver. $O$ bebê deve poder aceder totalmente ao corpo vivo da mãe" (Winnicott, 2001, p. 115).

Esse ambiente intersubjetivo serve também para apresentar o mundo à criança e logo efetuar um trabalho de desilusão após ter dado a ilusão de que o mundo podia ser criado a partir da necessidade e da imaginação (Winnicott, 2001, p. 118).

Nesse desenvolvimento afetivo, o rosto da mãe tem o rol de precursor do espelho, providenciando um entorno ainda não separado da criança, onde ela encontra a si mesma, pois o rosto reflete o que a mãe vê (Winnicott, 1991b, pp. 149-159). Colocaria aqui mesmo a virada do vidente para visível comentada por Merleau-Ponty na filosofia da carne. Esse entorno originário inter-humano e intersubjetivo é que providencia a 
carne do mundo, da qual surgem progressiva e contemporaneamente $o$ sujeito e o outro. Ainda que Merleau-Ponty se refira ao estádio do espeIho lacaniano, afirmamos que é essa descrição winnicottiana que fornece a dimensão arcaica da instituição da intersubjetividade, onde os holding, handling e object presenting da mãe facilitam para a criança criar simultaneamente interior e exterior, self e outro, numa reversão da carne de tocante a tangível, vidente a visível.

A experiência encarnada da amamentação, como afirma Winnicott (1991a, p. 47) em “The Baby as a Person”,'é ao mesmo tempo imaginária: a experiência do seio é uma maneira de criar a realidade encontrando-a. Para a criança afortunada, o mundo se comporta de maneira adaptada à sua imaginação, agregando-a e enriquecendo-a. Conforme explicita Winnicott (1991a), quando a mãe oferece sincronizadamente o seio, a criança adquire a ilusão de que o criou a partir da necessidade, da vontade e das primeiras pulsões do amor primitivo. Quando repetida, essa experiência é acompanhada pelo sentimento de que o que era desejado foi criado, e pode ser conteúdo no mundo, numa relação viva entre realidades interna e externa, criatividade primária e mundo. $O$ sentimento da realidade do mundo, conforme explicita Winnicott (1991a) em "The World in Small Doses", é progressivamente adquirido e procede dessa mistura originária de real e imaginário, que o trabalho da mãe ajuda a distinguir gradativamente.

Nesse vaivém entre interior e exterior, realidade psíquica e intersubjetiva, o afeto é definido numa dialética entre pulsões e maternidade (mothering). O lactante é ao mesmo tempo princípio vital," going concern", e relacionamento com a mãe, numa dialética entre pulsões e entorno. As pulsões parciais procedendo das excitações corporais, associadas ao amor primitivo, à cólera e às frustrações, são inversamente proporcionais ao holding e handling da mãe. Quando a ausência da mãe se prolonga um certo tempo, esvai-se sua representação interna pela criança, deixando-a recorrer a gratificações autossensuais e atividades autoeróticas (Winnicott, 1991a, p. 170).

Porém, existe também um outro espaço, paralelo ao da fantasia e da pulsão sexual: a área transicional do jogo e da cultura.

\section{Área transicional e Phantasia}

Objetos e fenômenos transicionais acontecem numa área submetida a uma série de paradoxos que não devem ser reduzidos. Situados entre o interior e o exterior, o individual e o interpessoal, não são nem concebidos subjetivamente nem percebidos objetivamente (Winnicott, 1991 b, pp. 2-3). Primeira aquisição não ego da criança, o objeto transicional permite passar de um universo mágico onipotente ao reconhecimento 
de uma realidade diferente do mundo imaginário, prolongando a ilusão de que o que foi desejado foi criado e encontrado. Figurando a união e a separação com a mãe, o objeto transicional é o signo de uma "capacidade de estar só," paradoxalmente construída somente na presença da mãe. Essa área se estende ao jogo (playing) no qual a criança manipula fenômenos exteriores investindo-os de significações da sua realidade psíquica, e na experiência cultural.

Entre a minha percepção e a do outro, encontra-se, para MerleauPonty, um espaço intercorporal e intersensorial, base da intersubjetividade. Asseveraria que esse espaço é muito similar à área transicional. $O$ ato psíquico convocado na área transicional não é nem percepção (a criança não percebe o objeto só enquanto objeto exterior) nem imaginação (o objeto transicional tem uma dimensão da realidade exterior também). Do mesmo modo, o encontro com o outro procede dessa mistura de atos psíquicos. Para reconhecer o outro enquanto outro (e não objetivá-lo como faria percebendo uma cadeira ou uma lâmpada), não o percebo somente (percebo unicamente o seu corpo físico, Körper, mas nenhuma vida interna), mas também não o imagino somente (o que seria uma mera fantasia do outro ou um modo psicótico de relacionamento com ela/ele). Ao perceber o Körper do outro, como notava já Husserl, efetuo uma apresentação do seu Leib, corpo vivido e vivo, a partir do meu próprio Leib, único corpo que posso experimentar como corpo vivo do interior. $O$ ato de consciência aqui mobilizado não é, portanto, nem percepção nem imaginação, mas o que Marc Richir, retomando a teoria husserliana, chama de Phantasia (Richir, 2000, p. 174). Essa é um ato psíquico proteiforme, sem forma fixada, intermitente, flutuante, descontínuo, fora da temporalidade linear da percepção, preconsciente e inconsciente. Pode ser transposta numa imagem ou numa fantasia, mas aquelas já são uma forma de fixar a não posicionalidade da Phantasia.

Sustenho que o espaço intersubjetivo e a área transicional fundamentam-se nesse registro da Phantasia e que, do mesmo modo, o afeto e a busca em figurabilidade do afeto são vinculados a esse registro.

A gênese winnicottiana da intersubjetividade mostra que não há solus ipse primário nem mônada original a partir dos quais adviria uma problemática passagem ao outro, mas uma estrutura já intersubjetiva, um "êxtase original" (Merleau-Ponty, 1953/1989, p. 224), conforme escrevia Merleau-Ponty, do qual o outro e o meu corpo surgem contemporaneamente.

A Phantasia caracterizando o espaço transicional e a intersubjetividade, na sua não posicionalidade, antes de ser configurada em imagem ou fantasia, serve para modelizar a busca em figurabilidade do afeto acedendo à consciência. 


\section{Tranferência, intersubjetividade e figurabilidade do afeto}

Essa noção de busca em figurabilidade do afeto me parece central, tanto teórica como clinicamente, principalmente com formas contemporâneas da psicopatologia.

\section{O afeto na teoria freudiana e a busca em figurabilidade}

Em primeiro lugar, a importância teórica dessa noção é a de permitir a resolução de algumas dificuldades ligadas à teorização do afeto por Freud. Na metapsicologia freudiana, a pulsão tem dois representantes: 0 representante-representação (Vorstellungsrepresentanz) e o afeto. Esse parece colocado a uma distância igual do corpo e do ego e convoca, de uma forma distinta, a consciência e o inconsciente. Quando consciente, o afeto é a coloração afetiva de uma situação, uma qualidade apreensível pelo ego. Inconsciente é um processo energético de tensão e descarga, à base dos movimentos somático-psíquicos inconscientes.

As representações inconscientes correspondem a traços mnemônicos dissociados do seu contexto consciente, recalcadas, e reorganizadas, ou atraídas pelo recalcamento preexistente. Uma representação pode ser segmentada, e os processos primários podem concernir somente uma parte dela. $\mathrm{O}$ afeto, ao contrário, não se decompõe com o recalcamento. Sendo a finalidade do recalcamento evitar o desprazer, o destino do afeto se revela mais importante do que o da representação. Esse destino é ou uma repressão total, ou uma manifestação sob uma coloração afetiva qualquer, ou a transformação total em angústia (Freud, 1915/1968). Depois do recalcamento, o afeto desaparece totalmente, ou é totalmente reconstruído.

No outro sentido, antes do recalcamento acontecer, numa perspectiva partindo do inconsciente para chegar à consciência, o afeto pode ser considerado como movimento de uma pulsão em busca de "representância" ou figurabilidade - não uso deliberadamente aqui o termo representação, para diferenciar esse movimento da representação na pulsão. Freud descreve dois destinos do afeto: numa concepção "arrombadora", na qual o afeto chega diretamente do sistema inconsciente à consciência, "sempre tem um caráter de angústia, contra a qual todos os afetos 'recalcados' são intercambiados" (Freud, 1915/1968, p. 86). Numa concepção vicariante, o afeto se desenvolve a partir de uma representação substitutiva que a pulsão encontra no consciente. Se a concepção vicariante caracteriza uma grande parte dos mascaramentos e ocultações próprios à neurose, a concepção arrombadora é que define, para nós, a irrupção do afeto nos movimentos de angústia das psicopatologias contemporâneas.

Nem verdadeiramente consciente, por ter sido inibido no seu desenvolvimento, nem completamente inconsciente, porque existe somente 
num estado"rudimentar" no sistema inconsciente, o afeto estabelece uma constante transição entre os dois. A barra do inconsciente não detém os afetos, como faz pelas representações, mas os transforma. A abordagem de uma fenomenologia da afetividade - que presto a Merleau-Ponty consiste em tentar levantar essa barra para trazer à tona o afeto inconsciente sedimentado no afeto consciente.

Todavia, quando Freud teoriza o afeto como quantidade, aparecem verdadeiros problemas epistemológicos. Cabe perguntar de que serve essa abordagem quantitativa. A quantidade, a meu parecer, não tem nenhum valor de medida na metapsicologia freudiana: é um enigma e um instrumento heurístico. Aparece só como o "demais", na concepção traumática do afeto na angústia, um excesso que desestabiliza, arromba e transtorna. A abordagem quantitativa, ademais, apresenta o interesse de apontar um "irrepresentável analítico". Como ressalta Green (1973, p. 261), o ponto de vista econômico introduz também a noção de transformação pelo trabalho. Acredito que essa noção de trabalho como medida da exigência imposta ao psíquico pelo seu vínculo com o somático, como transformação de energia livre em energia ligada, de pulsão em figuração psíquica - permite abordar o afeto como uma demanda de figuração.

Não definiria essa busca de figurabilidade como representação, Vorstellung, mas como apresentação, Darstellung. A representação, herdada da ontologia clássica, é uma imagem mental que remete a uma outra realidade, recusada pela fenomenologia - não há representações internas, mas formas de se tender intencionalmente em direção a objetos. A apresentação, entretanto, é direta, imediatamente perceptível, sem delegação. Essa apresentação corresponde, para nós, a um trabalho de figurabilidade do afeto. $O$ modelo teórico dessa busca em figurabilidade pode ser encontrado, a nosso ver, na intersubjetividade, tal como é teorizada por Merleau-Ponty e Winnicott, e no ato psíquico de Phantasia.

\section{Destinos do afeto e figurabilidade na clínica contemporânea}

Consideramos que os destinos dos afetos são o alvo central da clínica analítica, pois os movimentos afetivos são ao mesmo tempo os objetivos, os reveladores e as ferramentas do trabalho do analista. Já nos Estudos sobre a Histeria, a "abreação" visava o desbloqueio do afeto atado, favorecendo assim uma nova mobilidade afetiva quando uma grande parte da afetividade era retirada à consciência. Massiva ou progressiva (integrando a memória numa série de associações), a abreação almeja, na sua ação terapêutica, a "carga afetiva" da memória (Freud, 1895/1971, p.4).

À medida que a teoria freudiana evoluiu, abandonando a hipnose, adotando a regra de associações livres, a primazia da fantasia e o traba- 
Iho sobre a resistência, a abreação foi substituída pelo conceito de perlaboração (Durcharbeitung). Essa estende no tempo o trabalho afetivo da abreação (Freud, 1904-1919/1953, p. 115): ela é uma verdadeira prova afetiva, passando, como indicam Laplanche e Pontalis (1967, p. 305), da mera aceitação intelectual para uma convicção fundada sobre a experiência vivida.

A importância da afetividade na sessão é salientada por Freud no texto "Construções em análise", onde o analisando tem que lembrar algumas experiências e as moções afetivas suscitadas por elas e ligadas a elas (Freud, 1921-1938/1985, p. 270). O trabalho analítico visa essas moções afetivas muito mais do que a lembrança de representações (que são só um meio de aceder a essas moções).

As memórias do analisando são comparadas por Freud a formações delirantes, e às construções do analista, que apresentam, como o delírio, um pedaço de "verdade histórica". Essa verdade não é a conformação de uma representação a um conteúdo, mas um movimento afetivo. Se, como mostra a memória encobridora, na sessão, a fantasia, o delírio ou a reconstrução de uma memória "valem" tanto quanto uma memória "real", é porque são todos caracterizados por uma mesma qualidade afetiva. Todos manifestam a mesma busca em figurabilidade do afeto.

Essa busca em figurabilidade manifesta-se ainda mais em pacientes que apresentam manifestações contemporâneas da psicopatologia, cujo aspecto comum é uma grande dificuldade em simbolizar. Na pobreza fantasmática que atravessam, a elaboração psíquica é curto-circuitada e as passagens ao ato são sistemáticas. Isso é acompanhado frequentemente de uma forte ambivalência nas relações de objeto e de numerosos ataques contra o outro para evitar a aflição de uma perda de objeto. As defesas - aditivas, psicossomáticas e depressivas - são muito custosas, já que não se elaborou uma "capacidade de estar só": os sintomas, posturas e gestos corporais, afetos de angústia, ódio e raiva vêm revelar uma falha que não é da ordem da castração, mas da existência mesma. Portanto, os afetos aqui concernidos são ainda menos ligados a representações, e o trabalho analítico não consiste em vinculá-los a representações recalcadas, mas encaminhá-los em direção a uma figurabilidade que nunca teve lugar. Isso se possibilita só por via de uma intersubjetividade particular na transferência, implicando os corpos do analista e do analisando e tentando fazer viver a intersubjetivade primária do entorno, que não teve lugar.

O encaminhamento dessas moções afetivas em direção a uma figuração acontece na transferência. Entretanto, com pacientes "contemporâneos", essa transferência recorre ainda mais à intersubjetividade originária.

No início da teoria freudiana, a transferência é considerada só como deslocamento do afeto de uma representação - passada, recalcada - para 
uma outra - atual.É definida, na"Dinâmica da transferência",como reedição de alguns "clichês" e formas da vida amorosa conscientes e inconscientes, integrando o analista numa das "séries psíquicas" ou imagens do paciente (Freud, 1904-1919/1953, pp. 50-52). Essa repetição da transferência tem sempre um conteúdo relacionado com a vida sexual infantil (Freud, 19151923/1982, p. 58).

Aliás, de um lado, a transferência positiva é reconhecida como "a verdadeira força motriz da participação do paciente no trabalho analítico" (Freud, 1946/1985, p. 43); mas, por outro lado, a transferência aparece como uma exageração da afetividade do paciente. É uma erupção afetiva "que ultrapassa a medida e afasta-se, por seu caráter e sua intensidade, daquilo que seria normal, racional" (Freud, 1904-1919/1953, p. 52), acontecendo quando um acesso à verdade histórica ocorre. É definida como "incêndio no teatro", intensificação afetiva à qual o analista não responde diretamente, mas deixa subsistir como força motriz da mudança (Freud, 1904-1919/1953, p. 123).

Essa intensificação afetiva é ainda mais importante com pacientes contemporâneos: se os "neuróticos clássicos" sofrem de uma falta de reconhecimento das moções afetivas por elas serem separadas das suas representações recalcadas, para outro tipo de paciente essas moções são ainda mais frenéticas e arrombadoras porque nunca foram vinculadas a representações, nem sequer recalcadas. Elas ainda estão num processo de busca de figurabilidade.

Aqui ocorre o que Fédida (1988) chamava de "estranheza da transferência", uma repetição alucinatória de afetos e fragmentos de sensações vividas, mas não inscritos, em busca de serem figurados.

Essa busca em figurabilidade dos afetos, própria às psicopatologias contemporâneas, introduz a necessidade, na prática clínica, de mudar alguns elementos do setting clássico, com o objetivo de estabelecer, com o paciente, aquela intersubjetividade primária que nunca se inscreveu realmente. Para conseguir um duplo movimento de identificação do afeto na sua psique, mas também na do analisando, o analista precisa de uma empatia particular, vinculando as redes associativas do analisando com as suas. Nesse contexto, a figuração do afeto é o objetivo essencial.Tratase de providenciar, nas "imagens autóctones" do analista, um material sensorial, encarnado, corporal, suscetível a traduzir aquilo que nunca recebeu forma nem figuração no analisando. Trata-se de providenciar palavras resgatando vivências corporais não figuradas, levantando mais capacidade sensorial.

A transferência visa aqui o surgimento de afetos e sensações não integrados, recorre a vivências corporais e mobiliza a presença encarnada tanto do analisando como do analista. Nesse movimento, a intersubjetividade é fundamental: ela estabelece um entorno real-imaginário, alucinatório, a partir do qual se subjetivam o sujeito e o outro. Só um es- 
tabelecimento dessa intersubjetividade originária que não foi inscrita permite, a meu ver, a regressão alucinatória, visando a figurabilidade do afeto e a integração de impressões sensíveis e traumáticas não resolvidas. O que está em jogo é tentar constituir, na relação transferencial, aquilo que não se inscreveu na experiência originária com o outro.

Cabe ressaltar que se trata especificamente do ato psíquico de Phantasia, nem percepção nem imaginação (ou fantasia), aquele ato que caracteriza o encontro intersubjetivo e a área transicional. Na intersubjetividade e pela Phantasia, pode-se esperar dar figuração a fenômenos que precisarão ser constituídos e psiquizados, não só rememorados como parte de uma realidade que já foi vivida e recalcada.

\section{Conclusão}

A passagem da questão da alteridade para a questão de intersubjetividade não é uma mera preocupação teórica na evolução especulativa, conduzindo as filosofias do sujeito para as da intersubjetividade. Essa questão parece central na abordagem da clínica e no desenvolvimento de perspectivas teóricas capazes de dar conta dessa clínica e de permitir lidar com ela.

Se Freud limitou o uso da psicanálise à neurose, considerando impossível essa abordagem com psicóticos ou pacientes "gravemente neuróticos", cujo ego não permite uma aliança terapêutica, é provavelmente por ter inscrito a teoria psicanalítica no enquadre de filosofias do sujeito, limitando-se à mera questão da alteridade. $O$ conceito de narcisismo primário, que se revela muito problemático teórica e clinicamente, procede dessa postura, colocando primeiro o sujeito e o outro como variação segunda do mesmo. A perspectiva de uma clínica contemporânea conduz, ao revés, a questionar esse enquadre e pensar filosoficamente, a partir da questão da intersubjetividade, um relacionamento primeiro precedendo o sujeito e o outro e permitindo que surjam juntos. Nessa questão da intersubjetividade, jaz a possibilidade teórica de conceber a transferência como inscrição daquele relacionamento originário que não se constituiu e que só permite ao sujeito elaborar uma "capacidade de estar só". Obviamente, as modalidades das vivências afetivas na transferência e na verdadeira "loucura da contratransferência" são particulares, apresentam grandes dificuldades clínicas e implicam necessárias revisitações do tratamento tipo da cura analítica.

Se se pode verdadeiramente encontrar muitas semelhanças entre Merleau-Ponty e Winnicott, através da Phantasia intersubjetiva e da área transicional, o filósofo, porém, não apresenta nenhum modo de dar conta do fracasso em figurabilidade do afeto. A fenomenologia de MerleauPonty apresenta a visão feliz de um mundo harmonioso e sereno, livre da 
negatividade da morte, da pulsão ou da violência. Portanto, ela não permite tematizar nenhum "fear of breakdown", medo de derrubamento relativo à ruptura da continuidade na existência da criança, ou a ansiedade impensável (primitive agony) que aponta a falha em simbolizar e figurar o afeto.

Genealogy of Intersubjectivity and Affect Figurability:Winnicott and Merleau-Ponty

Abstract: This article aims to tackle the question of intersubjectivity, beyond the traditional philosophical question of otherness. This issue is fundamental in philosophy, but also in psychoanalysis and psychopathology, since it involves the constitution of a relationship with the other, an experience based on infantile memory and never definitively acquired. This involves various theoretical and clinical experiences, as far as the treatment of contemporary psychopathological forms is concerned.The author shows how Merleau-Ponty's interest for the body and the other echoes winnicottian psychoanalysis and how both reveal a mental act specific to intersubjectivity and affect figurability, lying between perception and hallucination, inside and outside, subject and other.

Keywords: Intersubjectivity. Affect. Psychoanalysis. Phenomenology. Merleau-Ponty (Maurice). Winnicott (Donald Woods).

Généalogie de l'intersubjectivité et figurabilité de l'affect:Winnicott et Merleau-Ponty

Résumé: Cet article tente d'aborder la question de l'intersubjectivité, par delà la traditionnelle question de l'altérité. Non seulement cette question est fondamentale en philosophie, mais elle apparaît centrale pour la psychanalyse et la psychopathologie, puisqu'il s'agit ici de la constitution de la relation avec autrui, une expérience fondée sur la mémoire de l'infantile, et jamais acquise de manière définitive. L'auteur montre comment la centralité du corps et d'autrui dans la phénoménologie de Merleau-Ponty a des échos dans la psychanalyse winnicottienne, et comment toutes deux révèlent un acte psychique propre à l'intersubjectivité et à la figurabilité de l'affect, entre perception et hallucination, intérieur et extérieur, sujet et autrui.

Mots-clés: Intersubjectivité. Affect. Psychanalyse. Phénoménologie. Merleau-Ponty (Maurice). Winnicott (Donald Woods). 
Genealogía de la intersubjectividad y figurabilidad del afecto: Winnicott y MerleauPonty

Resumen:Este artículo pretende abordar la cuestión filosófica de la intersubjectividad, más allá de la cuestión tradicional de la alteridad. La preeminencia de esta cuestión no concierne sólo la filosofía: aparece central en la perspectiva del psicoanálisis y de la psicopatología, pues se trata aquí de la constitución del relacionamiento con el otro, una experiencia fundada sobre la memoria infantil y nunca adquirida de forma definitiva. El autor evidencia como la centralidad del cuerpo y del otro en la fenomenología de Merleau-Ponty tiene ecos en el psicoanálisis winnicottiano, y como ambos revelan un acto psíquico específico propio a la intersubjectividad y a la figuración del afecto, entre percepción y alucinación, interior y exterior, sujeto y otro.

Palabras clave: Intersubjectividad. Afecto. Psiconanálisis. Fenomenología. MerleauPonty (Maurice). Winnicott (Donald Woods).

\section{Referências}

Beaune, D., \& Ayouch, T. (2009). Folies contemporaines. Paris: L'Harmattan.

Bonan, R. (2001). Le problème de l'intersubjectivité dans la philosophie de Merleau-Ponty. La dimension communem (Vol. 1). Paris: L'Harmattan.

Fédida, P. (1992). Autoerotismo e autismo: condições de eficácia de um paradigma em psicopatologia. In Nome, figura e memória - a linguagem na situação psicanalítica. São Paulo: Escuta.

Freud, S. (1953). La technique psychanalytique (A. Berman, trad.). Paris: P.U.F. (Trabalho original publicado em 1904-1919)

Freud, S. (1968). Métapsychologie (J. Laplanche \& J.-B. Pontalis, trads.). Paris: Gallimard. (Trabalho original publicado em 1915)

Freud, S. (1971). Etudes sur l'hystérie (A. Berman, trad.). Paris: P.U.F. (Trabalho original publicado em 1895)

Freud, S. (1982). Essais de psychanalyse (J. Laplanche, dir. trad.). Paris: Payot. (Trabalho original publicado em 1915-1923)

Freud, S. (1985). Résultats, idées, problèmes I/. Paris: P.U.F. (Trabalho original publicado em 1921-1938) 
Freud, S. (1985). Abrége de psychanalyse (A. Berman, trad., revue et corrigée par J. Laplanche). Paris: P.U.F. (Trabalho original publicado em 1946)

Green, A. (1973). Le Discours vivant. Paris: P.U.F.

Green, A. (1999). Sur la discrimination et l'indiscrimination affect-représentation. Revue Française de Psychanalyse, (1), 217-271. Tome 63: L'affect et sa perversion.

Husserl, E. (1947). Méditations cartésiennes (E. Levinas, trad.). Paris: Vrin.

Husserl, E. (1950). Idées directrices pour une phénoménologie (P. Ricoeur, trad.). Paris: Gallimard.

Husserl, E. (1982). Idées directrices pour une phénoménologie. Livre II, Recherches phénoménologiques pour la constitution (E. Escoubas, trad.). Paris: P.U.F.

Husserl, E. (1998). Autour des Méditations cartésiennes Sur l'intersubjectivité (N. Depraz \& P. Vandevelde, trads., revue par M. Richir). Grenoble: Jérôme Millon. (Trabalho original publicado em 1929-1932)

Laplanche, J., \& Pontalis, J.-B. (1967). Vocabulaire de la psychanalyse. Paris: P.U.F.

Merleau-Ponty, M. (1942). La structure du comportement. Paris: P.U.F.

Merleau-Ponty, M. (1945). Phénoménologie de la perception. Paris: Gallimard.

Merleau-Ponty, M. (1960a). Préface à L'CFuvre de Freud. A. Hesnard. Paris: Payot.

Merleau-Ponty, M. (1960b). Le visible et I'invisible. Paris: Gallimard.

Merleau-Ponty, M. (1988). Merleau-Ponty à la Sorbonne. Résumé de cours, 19491952. Paris: Gallimard.

Merleau-Ponty, M. (1989). Eloge de la philosophie et autres essais. Paris: Gallimard. (Trabalho original publicado em 1953)

Pontalis, J.-B. (1988). Aller et retour. In J.-B. Pontalis, Perdre de vue (pp. 195-205). Paris: Gallimard.

Richir, M. (2000). Phénoménologie en esquisses. Grenoble: Jérôme Millon.

Winnicott, D. W. (1991a). The child, the family and the outside world. London: Penguin.

Winnicott, D. W. (1991b). Playing and reality. London: Routledge. 
Winnicott, D.W. (2000). La crainte de l'effondrement et autres situations cliniques (J. Kalmanovitch \& M. Gribinski, trads.). Paris: Gallimard.

Winnicott, D.W. (2001). Le bébé en tant que personne. In D.W.Winnicott, L'enfant et le monde extérieur. Le développement des relations (A. Stronck-Robert, trad., pp. 103-112). Paris: Payot. 
Thamy Ayouch, maître de conférence (professor com cadeira vitalícia) na Université Lille III - Sciences Humaines, Lettres et Arts. Doutor pela Université Paris VII - Université Denis Diderot. Mestre em Filosofia e Psicopatologia pela Université Paris XII, Université Paris VII. Graduado em Filosofia, Psicologia Clínica e Literatura Inglesa. Atualmente é professor visitante estrangeiro do Departamento de Psicologia Clínica do Instituto de Psicologia da Universidade de São Paulo. Tem experiência na área de Filosofia e Psicologia Clínica, com ênfase em Psicanálise, Fenomenologia, Teoria Política, Teoria do Gênero. Endereço para correspondência: 18, Avenue du Président Hoover, 59000, Lille, França. Endereço eletrônico: thamy.ayouch@gmail.com

Recebido: 30/10/2011

Aceito: $23 / 02 / 2012$ 